\title{
KERAPATAN DAN VIABILITAS KONIDIA BEAUVERIA BASSIANA DAN METARHIZIUM ANISOPLIAE PADA MEDIA IN VITRO PH RENDAH
}

\author{
Lilian Rizkie $^{1}$, Siti Herlinda ${ }^{1,2,3}$, Suwandi ${ }^{1,2,3}$, Chandra Irsan ${ }^{1,2,3}$, \\ Susilawati $^{1,3,4}$, \& Benyamin Lakitan ${ }^{1,3,4}$ \\ 'Program Studi Magister Ilmu Tanaman, Fakultas Pertanian, Universitas Sriwijaya, Palembang \\ ${ }^{2}$ Jurusan Hama dan Penyakit Tumbuhan, Fakultas Pertanian, Universitas Sriwijaya, Indralaya \\ ${ }^{3}$ Pusat Unggulan Riset Pengembangan Lahan Suboptimal (PUR-PLSO), Universitas Sriwijaya, Palembang \\ ${ }^{4}$ Jurusan Budidaya Pertanian, Fakultas Pertanian, Universitas Sriwijaya, Indralaya \\ E-mail: sitiherlinda@unsri.ac.id
}

\begin{abstract}
Conidial density and viability of Beauveria bassiana and Metarhizium anisopliae grown on the low-pH in vitro medium . Liquid bioinsecticide with active ingredient from conidial entomopathogenic fungus has major constraints, namely short shelf life due to declining conidial viability and density is caused by low pH in the bioinsecticide carrier. This experiment aimed to measure the loss of conidial viability and density of Beauveria bassiana and Metarhizium anisopliae isolates grown on in vitro medium with low $\mathrm{pH}$. Entomopathogenic fungus isolates were used as much as 28 isolates grown on in vitro medium at low $\mathrm{pH}$, namely $\mathrm{pH} 5,4,3$, and 2 . The results showed that the fungus isolate that had the highest conidial density on in vitro medium at $\mathrm{pH} 5$ was found on isolates of $B$. bassiana with code BPcMs $\left(2.583 \times 10^{9}\right.$ conidia $\left.\mathrm{mL}^{-1}\right)$, while the lowest one was found on isolates of $B$. bassiana with code of BWS Pantura $\left(0.825 \times 10^{9}\right.$ conidia $\left.\mathrm{mL}^{-1}\right)$. All isolate conidial density from in vitro medium with $\mathrm{pH} 2$ decreased regularly. Conidial density of BPcMs isolate decreased to $2.483 \times 10^{9}$ conidia $\mathrm{mL}^{-1}$, as well as BWS Pantura isolate also decreased to $0.425 \times 10^{9}$ conidia $\mathrm{mL}^{-1}$. The highest conidial viability at $\mathrm{pH} 5$ was found on isolates of $B$. bassiana with code of BPcMs (51.572\%), while the lowest conidial viability was found on isolate of B. bassiana with BTmPc code (15.040\%). At pH 2, almost isolates tested had low conidial viability. The conidial viability of isolates BPcMs decreased to $47.037 \% \%$, while the isolates BTmPc also decreased to $12.778 \%$. Therefore, the lower of the $\mathrm{pH}$ of the in vitro medium was, the lower of conidial viability and density of B. bassiana and M. anisopliae was.
\end{abstract}

Key words: isolate, bioinsecticide, shelf life

\begin{abstract}
ABSTRAK
Kerapatan dan viabilitas konidia Beauveria bassiana dan Metarhizium anisopliae pada media in vitro $p H$ rendah. Bioinsektisida cair berbahan aktif konidia jamur entomopatogen memiliki kendala utama, yaitu singkatnya umur simpan yang diakibatkan menurunnya viabilitas dan kerapatan konidia yang salah satu penyebabnya adalah penurunan $\mathrm{pH}$ media pembawa. Penelitian ini bertujuan untuk mengukur penurunan viabilitas dan kerapatan konidia isolat-isolat Beauveria bassiana dan Metarhizium anisopliae yang ditumbuhkan pada media in vitro pada $\mathrm{pH}$ rendah. Isolat yang digunakan sebanyak 28 isolat yang ditumbuhkan pada media in vitro pada $\mathrm{pH}$ rendah, yaitu $\mathrm{pH} 5,4,3$, dan 2 . Hasil penelitian menunjukkan pada media in vitro pada $\mathrm{pH} 5$ isolat yang memiliki kerapatan tertinggi ditemukan pada isolat $B$. bassiana kode BPcMs $\left(2,583 \times 10^{9}\right.$ konidia $\mathrm{mL}^{-}$ $\left.{ }^{1}\right)$, sedangkan terendah pada isolat $B$. bassiana kode Bws Pantura $\left(0,825 \times 10^{9}\right.$ konidia $\left.\mathrm{mL}^{-1}\right)$. Semua isolat pada media in vitro

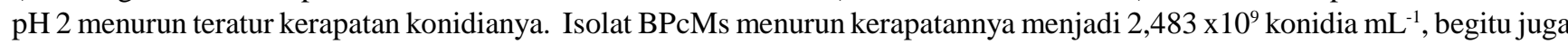
isolat Bws Pantura turun menjadi $0,425 \times 10^{9}$ konidia $\mathrm{mL}^{-1}$. Viabilitas konidia pada $\mathrm{pH} 5$ tertinggi ditemukan pada isolat $B$. bassiana kode BPcMs $(51,572 \%)$, sedangkan terendah pada isolat B. bassiana kode BTmPc $(15,040 \%)$. Pada pH 2, hampir semua isolat yang dicobakan mengalami penurunan viabilitas konidia. Viabilitas konidia isolat BPcMs menurun menjadi $47,037 \%$, sedangkan isolat BTmPc menurun menjadi $12,778 \%$. Dengan demikian, semakin rendah pH media in vitro, maka semakin turun viabilitas dan kerapatan konidia isolat B. bassiana dan M. anisopliae.
\end{abstract}

Kata kunci: isolat, bioinsektisida, umur simpan 


\section{PENDAHULUAN}

Jamur entomopatogen, seperti Beauveria bassiana dan Metarhizium anisopliae telah terbukti efektif (Prayogo, 2014) dan dapat membunuh berbagai spesies serangga hama. Misalnya, wereng cokelat (Nilaparvata lugens) (Herlinda et al., 2008a), wereng punggung putih (Sogatella furcifera) (Herlinda et al., 2008b), Spodoptera litura (Trizelia et al., 2011), kutu putih (Paracoccus marginatus) (Herlinda et al., 2012), penggerek batang padi kuning (Scirpophaga incertulas) (Thalib et al., 2013), Plutella xylostella (Nunilahwati et al., 2013), kutu daun (Aphis gossypii) (Riyanto et al., 2013), jangkrik (Gryllus sp.) (Ardiyati et al., 2015).

Aplikasi bioinsektisida berbahan aktif konidia jamur entomopatogen ini juga tidak berpengaruh buruk terhadap arthropoda bukan sasaran (non-target arthropods). Aplikasi bioinsektisida berbahan aktif konidia $B$. bassiana terbukti tidak menurunkan kelimpahan laba-laba (Herlinda et al., 2015a). Bioinsektisida tersebut juga tidak menurunkan kelimpahan serangga predator di ekosistem sawah (Herlinda et al., 2015b). Hasil penelitian terhadap bioinsektisida berbahan aktif konidia jamur entomopatogen dengan bahan pembawa kompos cair ternyata juga menghasilkan manfaat lebih, yaitu selain mengendalikan serangga hama sekaligus dapat meningkatkan pertumbuhan dan perkembangan tanaman (Herlinda et al., 2015b).

Dari kelebihan-kelebihan di atas, bioinsektisida juga memiliki banyak kendala dalam penerapannya. Bioinsektisida cair berbahan aktif konidia jamur entomopatogen memiliki kendala utama, yaitu singkatnya umur simpan yang diakibatkan menurunnya viabilitas dan kerapatan konidianya (Prayogo, 2006; Prayogo \& Santoso, 2013). Kemampuan bertahan hidup jamur entomopatogen dapat dipengaruhi suhu, kelambaban, dan faktor lingkungan fisik lainnya (Thalib et al., 2013; Suprayogi et al., 2015). Selain itu, penurunan viabilitas dan kerapatan konidia dipengaruhi oleh penurunan $\mathrm{pH}$ media pembawa (carrier) (Hanudin et al., 2010). Penurunan $\mathrm{pH}$ media pembawa sulit dihindari, semakin lama waktu penyimpanan maka akan semakin turun $\mathrm{pH}$ nya (Indarmawan et al., 2016). Jamur membutuhkan pH optimum berkisar 4-7 untuk pertumbuhannya (Srikandace et al., 2007). Untuk mengatasi permasalahan tersebut diperlukan konidia dari isolat yang mampu hidup di $\mathrm{pH}$ rendah.

Seleksi isolat guna mendapatkan isolat yang mampu bertahan di $\mathrm{pH}$ rendah perlu dilakukan. Oleh karena itu, penelitian ini bertujuan untuk mengukur penurunan viabilitas dan kerapatan konidia isolat-isolat
Beauveria bassiana dan Metarhizium anisopliae yang ditumbuhkan pada media in vitro pada $\mathrm{pH}$ rendah.

\section{METODE PENELITIAN}

Tempat dan Waktu. Penelitian ini dilaksanakan di Laboratorium Entomologi, Jurusan Hama dan Penyakit Tumbuhan, Fakultas Pertanian, Universitas Sriwijaya. Waktu penelitian dimulai pada bulan Januari sampai Agustus 2016. Suhu dan kelembapan rata-rata selama percobaan di laboratorium adalah $29,91{ }^{\circ} \mathrm{C}$ dan $90,20 \%$.

Pesiapan Jamur Entomopatogen. Isolat jamur entomopatogen yang digunakan pada penelitian ini adalah isolat B. bassiana dan M. anisopliae yang merupakan isolat koleksi pribadi Siti Herlinda yang dihasilkan dari penelitian-penelitian sebelumnya yang didanai oleh Kementerian Riset, Teknologi, dan Pendidikan Tinggi. Isolat-isolat tersebut dieksplorasi dari tanah rawa di Sumatera Selatan dan dari serangga-serangga yang ditemukan di agroekosistem di Sumatera Selatan. Isolatisolat tersebut selanjutnya ditumbuhkan pada media in vitro mengikuti metode Pham et al. (2009) dari media agar (Glucose Yeast Agar, GYA) selanjutnya diperbanyak di dalam media cair, Glucose Yeast Broth (GYB) yang metode pembuatannya mengikuti Herlinda et al. (2008b), selanjutnya biakan jamur entomopatogen tersebut digoyang di atas shaker pada kecepatan $120 \mathrm{rpm}$ per menit selama $3 \times 24$ jam pada suhu kamar $\left(29,91{ }^{\circ} \mathrm{C}\right)$ dan ruangan terang.

Untuk menghasilkan media in vitro dengan berbagai perlakuan $\mathrm{pH}$ yang diinginkan pada percobaan ini, maka digunakan metode Pham et al. (2009). Untuk mendapat variasi $\mathrm{pH}$ media in vitro sebesar $\mathrm{pH} 5,4,3$, dan 2, maka pada media GYB tersebut diteteskan larutan $\mathrm{HCl}$ berkisar 1-4 tetes mikropipet ukuran $10 \mu \mathrm{L}$, lalu diukur dengan $\mathrm{pH}$ Indikator. Setelah, media in vitro berpH sesuai perlakuan selanjutnya isolat-isolat jamur entomopatogen ditumbuhkan pada media tersebut.

\section{Pengamatan Kerapatan dan Viabilitas Jamur} Entomopatogen. Isolat yang digunakan sebanyak 28 isolat yang ditumbuhkan pada media in vitro pada $\mathrm{pH}$ rendah, yaitu $\mathrm{pH} 5,4,3$, dan 2. Media in vitro yang ber-pH rendah ini selanjutnya diinkubasikan selama $3 \times 24$ jam. Biakan jamur tersebut lalu diamati kerapatan konidianya. Sebanyak $1 \mathrm{~mL}$ biakan jamur diambil dari masing-masing isolat ditambah $9 \mathrm{~mL}$ air steril, dan proses ini selanjutnya diencerkan hingga 3 kali, seperti yang dilakukan Herlinda (2010). Setelah diencerkan suspensi jamur tersebut diamati di bawah mikroskop yang dilengkapi dengan haemocytometer. Metode 
penghitungan kerapatan konidia mengikuti Gabriel \& Riyatno (1989).

Untuk pengamatan viabilitas konidia dilakukan mengikuti cara Herlinda et al. (2010), yaitu suspensi dari biakan jamur tadi yang diencerkan sebanyak 3 kali pengenceran, lalu diambil menggunakan mikropipet ukuran $10 \mu \mathrm{L}$ sebanyak satu tetes yang diteteskan ke kaca preparat, lalu ditutup dengan cover glass. Untuk menjaga agar slide preparat tetap basah, maka di pinggir cover glass dioleskan kuteks bening. Setelah itu, slide preparat masing-masing isolat diamati perkecambahan konidianya setiap 24 jam sekali, yaitu pada 24,48 , dan $72 \mathrm{jam}$. Metode penghitungan viabilitas konidia mengikuti Gabriel \& Riyatno (1989).

Analisis Data. Perbedaan data kerapatan dan viabilitas konidia antar isolat dianalisis menggunakan Analisis Keragaman dan perlakuan disusun menggunakan rancangan acak lengkap. Bila terjadi perbedaan antar perlakuan, dilanjutkan dengan uji lanjut menggunakan Beda Nyata Terkecil (BNT) pada taraf nyata 5\% yang penghitungannya dibantu oleh program SAS-STAT pada SAS 6.12.

\section{HASIL DAN PEMBAHASAN}

\section{Kerapatan Konidia Jamur Entomoptogen pada Medium in vitro pH Rendah. Hasil penelitian} menunjukkan isolat yang ditumbuhkan pada media in vitro pada $\mathrm{pH} 5$ memiliki kerapatan konidia tertinggi ditemukan pada isolat $B$. bassiana berkode BPcMs $\left(2,583 \times 10^{9}\right.$ konidia $\left.\mathrm{mL}^{-1}\right)$, dan tidak berbeda nyata dengan kerapatan konidia isolat BTmTs. Kerapatan konidia terendah ditemukan pada isolat $B$. bassiana berkode Bws Pantura $\left(0,825 \times 10^{9}\right.$ konidia $\left.\mathrm{mL}^{-1}\right)$ dan tidak berbeda nyata dengan kerapatan konidia isolat $B$. bassiana berkode BTmTf (Tabel 1).

Pada media in vitro $\mathrm{pH} 4,3$, dan 2 , semua isolat mengalami penurunan kerapatan konidia. Penurunan kerapatan konidia paling rendah terjadi pada media in vitro $\mathrm{pH} 2$ dibandingkan $\mathrm{pH}$ lainnya. Pada media in vitro $\mathrm{pH} 2$, isolat BPcMs masih mampu memiliki kerapatan konidia sebesar $2,483 \times 10^{9}$ konidia $\mathrm{mL}^{-1}$, dan berbeda nyata dengan kerapatan konidia isolat lainnya. Isolat Bws Pantura pada media in vitro $\mathrm{pH} 2$ memiliki kerapatan konidia terendah hanya $0,425 \times 10^{9}$ konidia $\mathrm{mL}^{-1}$ dan berbeda tidak nyata dengan kerapatan konidia $B$. bassiana (isolat BTmPe dan BTmTf) dan M. anisopliae (MaMg dan MTmKt).

Umumnya semua isolat pada media in vitro mengalami penurunan kerapatan konidia seiring menurunnya $\mathrm{pH}$ media in vitro. Isolat $\mathrm{BPcMs}$ menurun kerapatannya dari $2,583 \times 10^{9}$ konidia $\mathrm{mL}^{-1}$ pada $\mathrm{pH} 5$ menjadi 2,542 x $10^{9}$ konidia $\mathrm{mL}^{-1}$ pada $\mathrm{pH} 3$, dan 2,483 x $10^{9}$ konidia $\mathrm{mL}^{-1}$ pada $\mathrm{pH} 2$. Namun pada $\mathrm{pH} 4$, kerapatan konidia isolat $\mathrm{BPcMs}$ menunjukkan kecenderungan berbeda, yaitu terjadi peningkatan

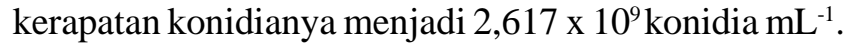
Pada isolat Bws Pantura, kerapatan konidianya menurun dari $0,825 \times 10^{9}$ konidia $\mathrm{mL}^{-1}$ pada $\mathrm{pH} 5$ menurun menjadi $0,775 \times 10^{9}$ konidia $\mathrm{mL}^{-1}$ pada $\mathrm{pH} 4,0,608 \times$ $10^{9}$ konidia $\mathrm{mL}^{-1}$ pada $\mathrm{pH} \mathrm{3}$, dan $0,425 \times 10^{9}$ konidia $\mathrm{mL}^{-1}$ pada $\mathrm{pH} 2$.

Walau hasil penelitian ini menunjukkan terjadi penurunan kerapatan konidia jamur entomopatogen bila $\mathrm{pH}$ medium in vitro diturunkan, namun beberapa isolat masih tumbuh dan berkembang baik dan menghasilkan kerapatan konidia tinggi pada $\mathrm{pH}$ rendah. $\mathrm{pH}$ yang digunakan pada penelitian ini merupakan $\mathrm{pH}$ di bawah ambang toleransi jamur entomopatogen. Jamur entomopatogen tumbuh dan berkembang baik pada $\mathrm{pH}$ netral (pH 6-8) (Karthikeyan et al., 2008; Fan et al., 2011). Dengan ditemukan isolat yang masih dapat menghasilkan kerapatan konidia yang tinggi pada $\mathrm{pH} 2$ pada penelitian ini merupakan harapan untuk menghasilkan bioinsektisida yang memiliki umur simpan yang lebih lama.

Isolat jamur entomopatogen yang mampu bertahan hidup dan menghasilkan kerapatan konidia tinggi pada $\mathrm{pH}$ rendah memiliki keunggulan lebih bila dijadikan bahan aktif bioinsektisida cair. Pertama, bioinsektisida yang mengandung bahan aktif konidia isolat jamur entomopatogen tersebut dapat memiliki umur simpan yang lebih lama sehingga perubahan $\mathrm{pH}$ pada bahan pembawa tidak mempengaruhi stabilitas konidia. Kedua, konidia isolat jamur entomopatogen tersebut yang mampu bertahan pada bahan pembawa $\mathrm{pH}$ rendah dapat meningkatkan kebugaran konidianya karena pada $\mathrm{pH}$ rendah isolat jamur entomopatogen dapat meningkat aktivitas enzim kitinasenya. Suryadi et al. (2013) menyatakan bila isolat jamur entomopatogen mampu bertahan pada $\mathrm{pH}$ rendah, maka isolat jamur entomopatogen tersebut dapat meningkatkan efektifitasnya karena isolat seperti itu memiliki aktivitas enzim kitinase yang tinggi. Jamur entomopatogen yang mampu bertahan pada $\mathrm{pH} 4$ mengalami aktivitas enzim kitinase tertinggi $\left(0,0053\right.$ unit $\left.\mathrm{mL}^{-1}\right)$ dibandingkan $\mathrm{pH} 3$. Semakin tinggi $\mathrm{pH}$ maka semakin menurun aktivitas enzim tersebut, namun pada $\mathrm{pH} 9$ dan 10 aktivitas enzim kembali meningkat (Suryadi et al., 2013). Semakin tinggi aktivitas enzim kitinase tersebut, maka semakin tinggi pula kemampuan isolat jamur entomopatogen tersebut untuk mematikan serangga hama (Rachmawaty, 2009). 
Tabel 1. Kerapatan konidia jamur entomopatogen pada berbagai $\mathrm{pH}$ media in vitro

\begin{tabular}{|c|c|c|c|c|c|c|}
\hline \multirow{2}{*}{ Isolat } & \multicolumn{6}{|c|}{ Kerapatan Konidia $\left(1 \times 10^{9}\right.$ konidia $\left./ \mathrm{mL}\right)$} \\
\hline & $\mathrm{pH} 5$ & $\mathrm{pH} 4$ & $\mathrm{pH} 3$ & & $\mathrm{pH} 2$ & \\
\hline BBY & $1,483(9,170)$ ef & $1,258(9,097)$ efg & $1,025(9,010)$ efgh & 0,808 & $(8,891)$ & defg \\
\hline BLePd & $233(9,091) \mathrm{cd}$ & $0,992(8,996)$ bc & $1,042(9,012)$ fghi & 0,933 & $(8,969)$ & ghij \\
\hline BPcMs & $2,583(9,411) \mathrm{m}$ & $2,617(9,418) 1$ & $2,542(9,404) \mathrm{p}$ & 2,483 & $(9,395)$ & $\mathrm{q}$ \\
\hline $\mathrm{BPcPd}$ & $1,042(9,016) b$ & $0,850(8,928) a b$ & $0,683(8,830) a b$ & 0,508 & $(8,700)$ & $\mathrm{ab}$ \\
\hline BPluS & $2,300(9,361) \operatorname{lm}$ & $2,000(9,300) \mathrm{j}$ & $1,633(9,213) \mathrm{lmn}$ & 1,317 & $(9,111)$ & $\mathrm{klm}$ \\
\hline BTmGa & ,183 $(9,339) \mathrm{klm}$ & $2,025(9,305) \mathrm{jk}$ & $2,017(9,305)$ nop & 1,750 & $(9,243)$ & op \\
\hline BTmMa & $1,192(9,072)$ bc & $1,167(9,062)$ cde & $0,775(8,887)$ abcd & 0,733 & $(8,859)$ & de \\
\hline $\mathrm{BTmMj}$ & $1,683(9,226)$ fghi & $1,483(9,169) \mathrm{h}$ & $1,475(9,168) \mathrm{ijklm}$ & 0,942 & $(8,966)$ & fghij \\
\hline BTmPc & $1,708(9,226)$ fghi & $1,558(9,192) \mathrm{hi}$ & $1,483(9,163)$ ijklm & 1,417 & $(9,149)$ & klmno \\
\hline BTmPd & $2,100(9,322) \mathrm{jkl}$ & $1,850(9,267) \mathrm{j}$ & $1,717(9,233) \mathrm{mno}$ & 1,500 & $(9,176)$ & $\operatorname{lmno}$ \\
\hline BTmPe & $1,417(9,151) \mathrm{de}$ & $1,000(9,000) \mathrm{c}$ & $0,800(8,901)$ bcde & 0,533 & $(8,725)$ & $a b c$ \\
\hline BTmRa & $1,475(9,166)$ ef & $1,392(9,143) \mathrm{fgh}$ & $1,100(9,039)$ fghi & 0,933 & $(8,970)$ & ghij \\
\hline BTmSm & $2,108(9,324) \mathrm{jkl}$ & $1,975(9,294) \mathrm{j}$ & $1,817(9,259) \mathrm{mno}$ & 1,658 & $(9,219)$ & nop \\
\hline BTmSo & $1,475(9,168)$ ef & $1,208(9,080)$ def & $0,692(8,839) a b$ & 0,658 & $(8,818)$ & $\mathrm{cd}$ \\
\hline BTmSr & $2,125(9,327) \mathrm{jkl}$ & $1,983(9,297) \mathrm{j}$ & $1,917(9,282)$ no & 1,567 & $(9,195)$ & mno \\
\hline BTmTf & $1,083(9,033) b c$ & $1,042(9,017) \mathrm{cd}$ & $0,725(8,855)$ abc & 0,483 & $(8,678)$ & $a b$ \\
\hline BTmTk & $1,600(9,198)$ efgh & $1,375(9,136)$ fgh & $1,025(9,009)$ efgh & 0,733 & $(8,861)$ & def \\
\hline $\mathrm{BTmTr}$ & $1,467(9,165)$ ef & $1,342(9,127)$ efgh & $0,900(8,951)$ cdef & 0,792 & $(8,891)$ & defg \\
\hline BTmTs & $2,433(9,386) \mathrm{lm}$ & $2,358(9,373) \mathrm{kl}$ & $2,158(9,334)$ op & 2,092 & $(9,320)$ & $\mathrm{pq}$ \\
\hline Bws Pantura & $0,825(8,912) \mathrm{a}$ & $0,775(8,883)$ a & $0,608(8,783) \mathrm{a}$ & 0,425 & $(8,625)$ & $\mathrm{a}$ \\
\hline $\mathrm{Ma}$ & $1,883(9,275)$ ijk & $1,800(9,254) \mathrm{ij}$ & $1,583(9,196) \mathrm{klmn}$ & 1,358 & $(9,129)$ & klmn \\
\hline MagIn & $1,833(9,263)$ ghij & $1,758(9,245) \mathrm{ij}$ & $1,467(9,165)$ ijklm & 1,158 & $(9,064)$ & $\mathrm{ijk}$ \\
\hline MAgPd & $1,692(9,227)$ fghi & $1,567(9,194)$ hi & $1,217(9,084)$ hij & 0,900 & $(8,950)$ & efgh \\
\hline $\mathrm{MaMg}$ & $1,433(9,154) \operatorname{def}$ & $1,358(9,131)$ efgh & $1,017(8,991)$ defgh & 0,483 & $(8,682)$ & $a b$ \\
\hline MTmJr & $1,650(9,217)$ efghi & $1,258(9,098)$ efg & $1,192(9,075)$ ghij & 1,008 & $(9,003)$ & hij \\
\hline MTmKt & $1,533(9,182)$ ef & $1,400(9,144)$ fgh & $0,942(8,965)$ cdefg & 0,567 & $(8,752)$ & $\mathrm{bc}$ \\
\hline MTmMs & $1,558(9,192)$ efg & $1,475(9,167) \mathrm{gh}$ & 1,317 (9,101) hijk & 0,925 & $(8,963)$ & efghi \\
\hline$\underline{\mathrm{MTmTr}}$ & $1,858(9,269)$ hijk & $1,825(9,261)$ ij & $1,325(9,122) \quad \mathrm{ijkl}$ & 1,183 & $(9,072)$ & $\mathrm{jkl}$ \\
\hline $\mathrm{FH}$ & $20,622 *$ & $27,696^{*}$ & $18,409 *$ & 30,703 & & \\
\hline$P$ Value & $1,78 \times 10^{-26}$ & $5,3 \times 10^{-31}$ & $8,7 \times 10^{-25}$ & 1,2 & $0^{-32}$ & \\
\hline BNT 5\% & 0,073 & 0,070 & 0,110 & 0,106 & & \\
\hline
\end{tabular}

Angka diikuti oleh huruf yang sama pada lajur yang sama berbeda tidak nyata, data di dalam kurung merupakan data hasil tranformasi arcsine.

Viabilitas Konidia Jamur Entomoptogen pada Medium in Vitro pH Rendah. Viabilitas konidia isolat jamur entomopatogen umumnya memiliki kecenderungan yang sama pada berbagai $\mathrm{pH}$ media in vitro. Pada 24 dan 48 jam setelah inkubasi, kecenderungan viabilitas konidia jamur entomopatogen (Tabel 2 dan 3) belum menunjukkan perbedaan yang signifikan antar isolat, sedangkan setelah diinkubasi selama 72 jam mulai menunjukkan perbedaan viabilitas yang nyata antar isolat (Tabel 4). Pada 72 jam setelah inkubasi, viabilitas konidia jamur entomopatogen pada pH 5 ditemukan tertinggi pada isolat $B$. bassiana berkode BPcMs $(51,572 \%)$. Viabilitas konidia terendah pada $\mathrm{pH}$
5 ditemukan pada isolat B. bassiana berkode BTmPc $(15,040 \%)$. Konsistensi data menunjukkan viabilitas konidia tertinggi ditemukan pada isolat $\mathrm{BPcMs}$ pada $\mathrm{pH}$ $4(46,065 \%)$, isolat BPcMs pada $\mathrm{pH} 3(36,218 \%)$, dan isolat BPcMs pada $\mathrm{pH} 2(47,037 \%)$. Namun, viabilitas konidia terendah ditemukan pada isolat yang berbedabeda, misalnya viabilitas konidia terendah ditemukan pada isolat $B$. bassiana berkode BTmPc $(15,040 \%)$ pada $\mathrm{pH}$ 5, isolat $B$. bassiana berkode BTmSm pada $\mathrm{pH} 4$ $(14,825 \%)$, isolat B. bassiana berkode BTmTr pada $\mathrm{pH}$ $3(8,333 \%)$, dan isolat B. bassiana berkode BTmTr pada pH $2(8,889 \%)$ akan tetapi ketiga isolat ini tidak berbeda nyata dengan isolat BTmPc (Tabel 4). 
Tabel 2. Viabilitas konidia jamur entomopatogen pada berbagai $\mathrm{pH}$ media in vitro yang diamati pada 24 jam setelah inkubasi

\begin{tabular}{|c|c|c|c|c|c|c|c|c|c|}
\hline \multirow{3}{*}{$\begin{array}{l}\text { Isolat } \\
\text { BBY }\end{array}$} & \multicolumn{9}{|c|}{ Viabilitas Konidia (\%) } \\
\hline & \multicolumn{2}{|c|}{ pH 5} & \multicolumn{2}{|c|}{ pH 4} & \multicolumn{2}{|c|}{ pH 3} & \multicolumn{3}{|c|}{ pH 2} \\
\hline & 12,632 & $(20,795)$ & 7,143 & $(12,665)$ & 4,762 & $(7,594)$ & 0,000 & $(0,286)$ & $\bar{a}$ \\
\hline BLePd & 15,741 & $(19,471)$ & 7,870 & $(13,488)$ & 3,704 & $(6,681)$ & 5,556 & $(8,223)$ & $a b c$ \\
\hline BPcMs & 23,684 & $(29,104)$ & 16,865 & $(24,125)$ & 20,192 & $(26,472)$ & 30,556 & $(33,510)$ & $\mathrm{e}$ \\
\hline $\mathrm{BPcPd}$ & 15,067 & $(22,340)$ & 9,722 & $(15,029)$ & 5,556 & $(8,223)$ & 0,000 & $(0,286)$ & $\mathrm{a}$ \\
\hline BPluS & 25,139 & $(29,662)$ & 20,707 & $(26,939)$ & 9,259 & $(14,618)$ & 14,815 & $(22,356)$ & cde \\
\hline BTmGa & 13,790 & $(21,548)$ & 10,501 & $(18,566)$ & 5,897 & $(11,608)$ & 6,667 & $(12,385)$ & $a b c$ \\
\hline ВТmMa & 14,537 & $(22,247)$ & 7,870 & $(13,488)$ & 4,762 & $(7,594)$ & 5,556 & $(8,223)$ & $a b c$ \\
\hline BTmMj & 17,350 & $(24,584)$ & 7,407 & $(9,566)$ & 2,564 & $(5,558)$ & 3,030 & $(6,040)$ & $a b$ \\
\hline BTmPc & 9,158 & $(17,430)$ & 8,625 & $(13,876)$ & 8,095 & $(13,643)$ & 3,889 & $(9,390)$ & $a b c$ \\
\hline BTmPd & 13,287 & $(21,245)$ & 12,078 & $(19,872)$ & 9,259 & $(14,618)$ & 11,243 & $(19,486)$ & bcde \\
\hline BTmPe & 11,111 & $(16,159)$ & 8,333 & $(13,899)$ & 10,317 & $(15,530)$ & 0,000 & $(0,286)$ & $\mathrm{a}$ \\
\hline BTmRa & 16,894 & $(24,170)$ & 10,438 & $(18,830)$ & 7,407 & $(13,076)$ & 3,333 & $(6,336)$ & $a b$ \\
\hline BTmSm & 11,409 & $(19,313)$ & 7,009 & $(12,602)$ & 9,141 & $(17,587)$ & 8,625 & $(17,066)$ & bcd \\
\hline BTmSo & 8,148 & $(13,725)$ & 7,500 & $(13,142)$ & 4,167 & $(7,093)$ & 4,167 & $(7,093)$ & $a b$ \\
\hline BTmSr & 10,470 & $(18,658)$ & 9,206 & $(17,473)$ & 5,000 & $(10,676)$ & 5,808 & $(11,538)$ & $a b c$ \\
\hline BTmTf & 7,870 & $(13,488)$ & 16,667 & $(23,803)$ & 7,500 & $(13,142)$ & 0,000 & $(0,286)$ & $\mathrm{a}$ \\
\hline BTmTk & 8,462 & $(13,938)$ & 18,241 & $(25,132)$ & 4,167 & $(7,093)$ & 3,030 & $(6,040)$ & $a b$ \\
\hline BTmTr & 12,795 & $(17,080)$ & 11,111 & $(15,961)$ & 4,167 & $(7,093)$ & 6,111 & $(11,833)$ & $a b c$ \\
\hline BTmTs & 22,024 & $(27,672)$ & 19,272 & $(25,930)$ & 20,177 & $(26,015)$ & 23,918 & $(29,184)$ & de \\
\hline Bws Pantura & 8,333 & $(13,899)$ & 8,333 & $(13,899)$ & 0,000 & $(0,286)$ & 0,000 & $(0,286)$ & $\mathrm{a}$ \\
\hline Мa & 16,783 & $(23,833)$ & 18,119 & $(24,640)$ & 9,764 & $(14,999)$ & 7,407 & $(13,076)$ & $a b c$ \\
\hline MagIn & 9,444 & $(14,543)$ & 10,370 & $(15,441)$ & 7,500 & $(13,142)$ & 3,704 & $(6,681)$ & $a b$ \\
\hline MAgPd & 10,847 & $(15,778)$ & 13,468 & $(21,394)$ & 11,574 & $(19,882)$ & 4,167 & $(7,093)$ & $a b$ \\
\hline $\mathrm{MaMg}$ & 9,764 & $(14,999)$ & 4,167 & $(7,093)$ & 7,870 & $(13,488)$ & 4,762 & $(7,594)$ & $a b$ \\
\hline MTmJr & 9,764 & $(14,999)$ & 12,037 & $(20,294)$ & 7,197 & $(12,847)$ & 3,704 & $(6,681)$ & $a b$ \\
\hline MTmKt & 16,239 & $(23,563)$ & 9,091 & $(14,358)$ & 4,167 & $(7,093)$ & 0,000 & $(0,286)$ & $\mathrm{a}$ \\
\hline MTmMs & 18,832 & $(25,259)$ & 14,444 & $(22,011)$ & 10,684 & $(15,825)$ & 10,370 & $(15,441)$ & bcd \\
\hline $\mathrm{MTmTr}$ & 14,899 & $(21,936)$ & 16,061 & $(23,413)$ & 10,370 & $(15,441)$ & 7,407 & $(13,076)$ & $a b c$ \\
\hline F Hitung & \multirow{3}{*}{\multicolumn{2}{|c|}{$\begin{array}{l}0,8139^{\text {tn }} \\
0,7219\end{array}$}} & \multirow{3}{*}{\multicolumn{2}{|c|}{$\begin{array}{l}0,9757^{\text {tn }} \\
0,5098\end{array}$}} & \multirow{3}{*}{\multicolumn{2}{|c|}{$\begin{array}{l}0,8600^{\text {tn }} \\
0,6624\end{array}$}} & \multirow{2}{*}{\multicolumn{2}{|c|}{$\begin{array}{l}2,708 * * \\
0.000287\end{array}$}} & \\
\hline$P$ Value & & & & & & & & & \\
\hline BNT 5\% & & & & & & & \multicolumn{2}{|c|}{14,576} & \\
\hline
\end{tabular}

Angka diikuti oleh huruf yang sama pada lajur yang sama berbeda tidak nyata, data di dalam kurung merupakan data hasil tranformasi arcsine.

Umumnya hampir semua isolat pada media in vitro menurun viabilitas konidianya seiring dengan menurunnya $\mathrm{pH}$ media in vitro. Isolat BPcMs menurun viabilitasnya dari $51,572 \%$ pada $\mathrm{pH} 5$ menjadi $46,065 \%$ pada $\mathrm{pH} 4,36,218 \%$ pada $\mathrm{pH} 3$, tetapi pada $\mathrm{pH} 2$ terjadi perbedaan kecenderungan karena viabilitas tidak turun $(47,037 \%)$. Isolat BTmSr menurun viabilitasnya dari $20,726 \%$ pada $\mathrm{pH} 5$ menjadi $18,413 \%$ pada $\mathrm{pH} 4$, $12,222 \%$ pada $\mathrm{pH} 3$, dan $11,364 \%$ pada $\mathrm{pH} 2$.

Banyak faktor yang mempengaruhi variasi viabilitas konidia jamur entomopatogen, yaitu jenis jamur dan asal isolat, umur jamur, media in vitro, media tempat perkecambahan, suhu, $\mathrm{pH}$, dan lama masa inkubasi
(Tanada \& Kaya, 1993). Pada penelitian ini, umur jamur, media in vitro, media tempat perkecambahan, suhu, dan lama inkubasi adalah sama sehingga tidak mempengaruhi variasi viabilitas, sedangkan jenis jamur dan asal jamur entomopatogen yang memiliki perbedaan dan $\mathrm{pH}$ divariasikan sesuai perlakuan. Jenis jamur entomopatogen yang digunakan ada 2 jenis, yaitu B. bassiana dan $M$. anisopliae, sedangkan asal jamur bervariasi ada yang berasal dari tanah rawa dan serangga inang. Isolat $B$. bassiana berkode BPcMs merupakan isolat yang berasal dari serangga inang, Pseudoplusia chalcites (Lepidoptera: Noctuidae) yang secara genetik dapat memiliki variasi dengan isolat B. bassiana yang berasal dari tanah. 
Tabel 3. Viabilitas konidia jamur entomopatogen pada berbagai $\mathrm{pH}$ media in vitro yang diamati pada $48 \mathrm{jam}$ setelah inkubasi

\begin{tabular}{|c|c|c|c|c|c|}
\hline \multirow{2}{*}{ Isolat } & \multicolumn{5}{|c|}{ Viabilitas Konidia (\%) } \\
\hline & pH 5 & & $\mathrm{pH} 4$ & $\mathrm{pH} 3$ & $\mathrm{pH} 2$ \\
\hline BBY & $18,717(25,468)$ & 14,286 & $(25,468)$ abcd & $11,429 \quad(25,468)$ & $4,167 \quad(7,093)$ \\
\hline BLePd & $18,519(21,225)$ & 12,037 & $(21,225) a b$ & $7,870 \quad(21,225)$ & $9,722(15,029)$ \\
\hline BPcMs & $38,670(38,445)$ & 33,433 & $(38,445) \mathrm{i}$ & $29,006(38,445)$ & $41,852(40,300)$ \\
\hline BPcPd & $18,771(25,225)$ & 15,278 & $(25,225)$ abcde & $11,111 \quad(25,225)$ & $5,556 \quad(8,223)$ \\
\hline BPluS & $36,944(37,419)$ & 32,323 & $(37,419)$ hi & $18,519 \quad(37,419)$ & $18,519(25,241)$ \\
\hline $\mathrm{BTmGa}$ & $25,794(30,265)$ & 25,946 & $(30,265)$ ghi & $17,692 \quad(30,265)$ & $13,704(21,490)$ \\
\hline $\mathrm{BTmMa}$ & $21,204(26,469)$ & 15,741 & $(26,469)$ abcde & $9,524 \quad(26,469)$ & $11,111(16,159)$ \\
\hline $\mathrm{BTmMj}$ & $19,915(26,457)$ & 15,278 & $(26,457)$ abcde & $8,159 \quad(26,457)$ & $9,764(14,999)$ \\
\hline $\mathrm{BTmPc}$ & $11,119(19,438)$ & 14,219 & $(19,438)$ abcd & $13,810 \quad(19,438)$ & $9,444(14,830)$ \\
\hline BTmPd & $18,415(24,777)$ & 19,870 & $(24,777)$ bcdefg & $12,963 \quad(24,777)$ & $16,402(23,714)$ \\
\hline BTmPe & $17,222(24,177)$ & 16,667 & $(24,177)$ abcdef & $15,079 \quad(24,177)$ & $4,762 \quad(7,594)$ \\
\hline BTmRa & $22,955(28,119)$ & 13,468 & $(28,119)$ abc & $14,815 \quad(28,119)$ & $10,833(15,852)$ \\
\hline BTmSm & $13,492(20,760)$ & 12,261 & $(20,760) a$ & $11,919 \quad(20,760)$ & $11,189(19,397)$ \\
\hline BTmSo & $16,296(23,344)$ & 14,537 & $(23,344)$ abcd & $11,574 \quad(23,344)$ & $8,333(10,191)$ \\
\hline $\mathrm{BTmSr}$ & $15,598(22,861)$ & 13,810 & $(22,861)$ abc & $10,000 \quad(22,861)$ & $8,586(13,977)$ \\
\hline BTmTf & $18,098(24,904)$ & 20,833 & $(24,904)$ cdefg & $10,833 \quad(24,904)$ & $5,556 \quad(8,223)$ \\
\hline BTmTk & $17,293(23,865)$ & 21,574 & $(23,865)$ cdefg & $7,870 \quad(23,865)$ & $6,061 \quad(8,604)$ \\
\hline $\mathrm{BTmTr}$ & $22,559(23,601)$ & 15,278 & $(23,601)$ abcde & $8,333 \quad(23,601)$ & $8,889(14,272)$ \\
\hline BTmTs & $37,202(37,547)$ & 32,400 & $(37,547) \mathrm{hi}$ & $27,717 \quad(37,547)$ & $35,137(36,350)$ \\
\hline Bws Pantura & $18,056(24,933)$ & 13,889 & $(24,933)$ abc & $3,704 \quad(24,933)$ & $4,762 \quad(7,594)$ \\
\hline Ma & $34,033(35,633)$ & 22,980 & $(35,633)$ efgh & $19,461 \quad(35,633)$ & $15,278(22,767)$ \\
\hline MagIn & $16,111(22,808)$ & 17,778 & $(22,808)$ abcdefg & $10,833 \quad(22,808)$ & $7,407(13,076)$ \\
\hline MAgPd & $17,328(24,160)$ & 17,172 & $(24,160)$ abcdefg & $15,278 \quad(24,160)$ & $8,333(10,191)$ \\
\hline $\mathrm{MaMg}$ & $13,468(21,394)$ & 12,037 & $(21,394) \mathrm{ab}$ & $11,574 \quad(21,394)$ & $9,524(10,961)$ \\
\hline MTmJr & $16,498(23,475)$ & 15,741 & $(23,475)$ abcde & $10,227 \quad(23,475)$ & $7,407(13,076)$ \\
\hline MTmKt & $18,803(25,436)$ & 15,455 & $(25,436)$ abcde & $12,500 \quad(25,436)$ & $5,556 \quad(8,223)$ \\
\hline MTmMs & $34,330(35,605)$ & 24,815 & $(35,605)$ fghi & $16,952 \quad(35,605)$ & $17,407(24,051)$ \\
\hline $\mathrm{MTmTr}$ & $17,929(24,500)$ & 22,424 & $(24,500)$ defg & $17,407 \quad(24,500)$ & $11,111(15,961)$ \\
\hline F Hitung & $1,3396^{\mathrm{tn}}$ & 4,040 & & $0,682^{\text {tn }}$ & $1,478^{\text {tn }}$ \\
\hline$P$ Value & 0,1577 & $5,08 \times$ & & 0,868 & 0,0914 \\
\hline BNT $5 \%$ & - & 6,274 & & & \\
\hline
\end{tabular}

Angka diikuti oleh huruf yang sama pada lajur yang sama berbeda tidak nyata, data di dalam kurung merupakan data hasil tranformasi arcsine.

Variasi viabilitas konidia isolat jamur entomopatogen dapat diakibatkan juga oleh pengaruh variasi $\mathrm{pH}$. Konidia isolat jamur akan berkecambah dengan baik pada $\mathrm{pH}$ netral ( $\mathrm{pH}$ 7) (Soundarapandian \& Chandra, 2007). Hampir semua isolat pada media in vitro menurun viabilitas konidianya seiring dengan menurunnya $\mathrm{pH}$ media in vitro tersebut. Pada penelitian ini isolat $B$. bassiana berkode BPcMs menunjukkan konsistensi yang tetap tinggi viabilitasnya baik di $\mathrm{pH} 5$ hingga $\mathrm{pH}$ 2. Pada media in vitro $\mathrm{pH} 2$ isolat ini masih menghasilkan viabilitas $47,037 \%$. Bila viabilitas konidia suatu isolat jamur entomopatogen yang masih tetap tinggi walau ditumbuhkan pada media in vitro $\mathrm{pH}$ rendah menunjukkan bahwa isolat tersebut unggul dan berpotensi menjadi bahan aktif yang efektif dalam pembuatan bioinsektisida. Dengan demikian, isolat $B$. bassiana berkode BPcMs memiliki potensi paling tinggi sebagai bahan aktif bioinsektisida.

Bila dikaitkan dengan kerapatan konidianya, konidia isolat $B$. bassiana berkode BPcMs memiliki kerapatan konidia paling tinggi. Kerapatan konidia yang tinggi ini diikuti dengan tertinggi viabilitasnya. Dari hasil penelitian ini, didapat satu isolat unggul bertahan pada $\mathrm{pH}$ rendah, yaitu isolat $B$. bassiana berkode BPcMs yang berasal dari serangga inang, $P$. chalcites. Dengan demikian, bila penelitian ini akan dilanjutkan untuk 
Tabel 4. Viabilitas konidia jamur entomopatogen pada berbagai $\mathrm{pH}$ media in vitro yang diamati pada $72 \mathrm{jam}$ setelah inkubasi

\begin{tabular}{|c|c|c|c|c|c|c|}
\hline \multirow{2}{*}{ Isolat } & \multicolumn{6}{|c|}{ Viabilitas Konidia (\%) } \\
\hline & & $\mathrm{pH} 5$ & & $\mathrm{pH} 4$ & pH 3 & pH 2 \\
\hline BBY & 22,421 & $(27,848) \mathrm{abcd}$ & 21,429 & $(27,365)$ abcd & $19,524(21,936) a b$ & $8,929(14,400) a b$ \\
\hline BLePd & 21,296 & $(22,872) \mathrm{a}$ & 19,907 & $(26,277)$ abcd & $15,741(19,471) a b$ & $13,889(18,127) a b c$ \\
\hline BPcMs & 51,572 & $(45,905) \mathrm{e}$ & 46,065 & $(42,740) \mathrm{g}$ & $36,218(36,852) b$ & $47,037(43,300) \mathrm{c}$ \\
\hline $\mathrm{BPcPd}$ & 22,475 & $(27,604) a b c$ & 19,444 & $(26,063) \mathrm{abcd}$ & $16,667(19,882) a b$ & $11,111(11,946) \mathrm{a}$ \\
\hline BPluS & 36,944 & $(37,419)$ abcde & 35,354 & $(36,479)$ efg & $25,926(30,505) a b$ & $22,222(27,620) a b c$ \\
\hline BTmGa & 37,500 & $(37,587)$ abcde & 43,773 & $(41,407) \mathrm{fg}$ & $26,923(31,155) a b$ & $17,037 \quad(23,706) a b c$ \\
\hline BTmMa & 28,704 & $(31,490)$ abcde & 19,907 & $(26,277) \mathrm{abcd}$ & $9,524(10,961) \mathrm{a}$ & $16,667(19,882) a b c$ \\
\hline BTmMj & 25,256 & $(30,085)$ abcde & 19,444 & $(25,866) a b c$ & $14,426(21,910) a b$ & $12,795(17,080) a b$ \\
\hline BTmPc & 15,040 & $(22,423) \mathrm{a}$ & 16,783 & $(23,833) a b$ & $19,221 \quad(25,475) a b$ & $12,778(17,234) \mathrm{ab}$ \\
\hline BTmPd & 23,543 & $(28,196) \mathrm{abcd}$ & 25,281 & $(30,120)$ abcde & $15,741(22,981) a b$ & $21,164(26,755) \mathrm{abc}$ \\
\hline BTmPe & 26,667 & $(30,857)$ abcde & 20,833 & $(26,902)$ abcd & $19,841(21,758) a b$ & $9,524(10,961) \mathrm{a}$ \\
\hline BTmRa & 30,152 & $(32,986)$ abcde & 17,172 & $(24,279) a b c$ & $19,577(26,153) a b$ & $17,500(20,074) a b c$ \\
\hline BTmSm & 18,353 & $(24,528) \mathrm{a}$ & 14,825 & $(22,402) \mathrm{a}$ & $11,667(16,240) a b$ & $13,753(21,269) \mathrm{abc}$ \\
\hline BTmSo & 20,741 & $(26,058) a b c$ & 18,241 & $(25,132) a b c$ & $19,444(21,850) a b$ & $12,500(12,778) \mathrm{ab}$ \\
\hline BTmSr & 20,726 & $(26,067) \mathrm{abc}$ & 18,413 & $(24,722) a b c$ & $12,222(16,982) a b$ & $11,364(15,945) \mathrm{ab}$ \\
\hline BTmTf & 24,158 & $(28,853) \mathrm{abcd}$ & 25,000 & $(29,489)$ abcde & $14,167(18,067) a b$ & $11,111(11,946) \mathrm{a}$ \\
\hline BTmTk & 19,858 & $(25,412) \mathrm{ab}$ & 25,741 & $(30,445)$ abcde & $12,037(16,586) a b$ & $9,091(10,685) \mathrm{a}$ \\
\hline $\mathrm{BTmTr}$ & 25,589 & $(25,340) a b$ & 18,981 & $(25,652) a b c$ & $8,333(10,191) \mathrm{a}$ & $8,889(14,272) \mathrm{ab}$ \\
\hline BTmTs & 48,214 & $(43,956) \mathrm{de}$ & 45,528 & $(42,432) \mathrm{g}$ & $35,623(36,498) b$ & $37,518(37,748) b c$ \\
\hline Bws Pantura & 23,611 & $(28,656) \mathrm{abcd}$ & 18,056 & $(24,933) a b c$ & $11,111(15,961) a b$ & $9,524(10,961) \mathrm{a}$ \\
\hline $\mathrm{Ma}$ & 45,221 & $(42,228)$ cde & 27,841 & $(31,823)$ bcde & $26,195(30,592) a b$ & $22,685(28,032) \mathrm{abc}$ \\
\hline MagIn & 18,889 & $(25,247) \mathrm{a}$ & 21,111 & $(26,936)$ abcd & $14,167(18,067) a b$ & $11,111(15,961) \mathrm{ab}$ \\
\hline MAgPd & 17,328 & $(24,160) \mathrm{a}$ & 20,202 & $(26,360)$ abcd & $15,278(22,767) a b$ & $12,500(12,778) \mathrm{ab}$ \\
\hline $\mathrm{MaMg}$ & 24,579 & $(29,543) \mathrm{abcd}$ & 15,741 & $(23,178) a$ & $15,278(18,752) a b$ & $14,286(13,822) a b$ \\
\hline MTmJr & 22,559 & $(27,111) a b c$ & 19,444 & $(25,558) a b c$ & $17,424(20,590) a b$ & $11,111(15,961) a b$ \\
\hline MTmKt & 23,932 & $(28,642) \mathrm{abcd}$ & 21,818 & $(27,762)$ abcd & $16,667(19,584) a b$ & $11,111(11,946) \mathrm{a}$ \\
\hline MTmMs & 43,932 & $(41,454)$ bcde & 31,852 & $(34,207)$ def & $24,858(29,267) a b$ & $24,444(28,943) \mathrm{abc}$ \\
\hline $\mathrm{MTmTr}$ & 23,485 & $(28,907) \mathrm{abcd}$ & 28,788 & $(32,288)$ cde & $20,741(22,548) a b$ & $14,815(18,846) \mathrm{abc}$ \\
\hline F Hitung & $1,298^{\text {tn }}$ & & $3,920 * *$ & & $0,667^{\text {tn }}$ & $0,837^{\text {tn }}$ \\
\hline$P$ Value & 0,184 & & $8,8 \times 10$ & & 0,883 & 0,692 \\
\hline BNT 5\% & 16,192 & & 8,172 & & 23,014 & 25,393 \\
\hline
\end{tabular}

Angka diikuti oleh huruf yang sama pada lajur yang sama berbeda tidak nyata, data di dalam kurung merupakan data hasil tranformasi arcsine.

memformulasikan bioinsektisidanya, maka isolat BPcMs dapat dijadikan calon bahan aktif bioinsektisida tersebut.

\section{SIMPULAN}

Pada media in vitro dengan $\mathrm{pH} 5$ isolat yang memiliki kerapatan tertinggi ditemukan pada isolat $B$. bassiana kode BPcMs $\left(2,583 \times 10^{9}\right.$ konidia $\left.\mathrm{mL}^{-1}\right)$, sedangkan terendah pada isolat $B$. bassiana kode Bws Pantura $\left(0,825 \times 10^{9}\right.$ konidia $\left.\mathrm{mL}^{-1}\right)$. Semua isolat pada media in vitro $\mathrm{pH} 2$ menurun secara teratur kerapatan konidianya. Isolat BPcMs menurun kerapatannya menjadi 2,483 x $10^{9}$ konidia $\mathrm{mL}^{-1}$, begitu juga isolat Bws Pantura turun menjadi $0,425 \times 10^{9}$ konidia $\mathrm{mL}^{-1}$. Viabilitas konidia pada $\mathrm{pH} 5$ tertinggi ditemukan pada isolat $B$. bassiana kode BPcMs $(51,572 \%)$, sedangkan terendah pada isolat $B$. bassiana kode BTmPc $(15,040 \%)$. Pada $\mathrm{pH} 2$, hampir semua isolat yang dicobakan mengalami penurunan viabilitas konidia. Viabilitas konidia isolat BPcMs menurun menjadi $47,037 \%$, sedangkan isolat $\mathrm{BTmPc}$ menurun menjadi $12,778 \%$. Dengan demikian, semakin rendah $\mathrm{pH}$ media in vitro, maka semakin turun viabilitas dan kerapatan konidia isolat B. bassiana dan M. anisopliae. 


\section{SANWACANA}

Penelitian ini dibiayai oleh Program Hibah Kompetensi (HIKOM) Tahun Anggaran 2016 sesuai Surat Direktur Riset dan Pengabdian Masyarakat, Direktorat Riset dan Pengabdian Masyarakat (DRPM), Direktorat Jenderal Penguatan Riset dan Pengembangan, Kementerian Riset, Teknologi, dan Pendidikan Tinggi, Nomor: 0299/E3/2016, tanggal 27 Januari 2016 dengan kontrak penelitian Nomor: 023/SP2H/LT/DRPM/II/2016 tanggal, 17 Februari 2016 yang penelitiannya diketuai oleh Siti Herlinda.

\section{DAFTAR PUSTAKA}

Ardiyati AT, Mudjiono G, \& Himawan T. 2015. Uji patogenisitas jamur entomopatogen Beauveria bassiana (Balsamo) Vuillemin pada jangkrik (Gryllus sp.) (Orthoptera: Gryllidae). Jurnal HPT 3(3): 43-51.

Fan Y, Zhang S, Kruer N, \& Keyhani NO. 2011. Highthroughput insertion mutagenesis and functional screening in the entomopathogenic fungus Beauveria bassiana. J. Invertebr. Pathol. 106(2): 274-279.

Gabriel BP \& Riyatno. 1989. Metarhizium anisopliae (Metch) Sor: Taksonomi, Patologi, Produksi dan Aplikasinya. Jakarta: Direktorat Perlindungan Tanaman Perkebunan, Departemen Pertanian.

Hanudin, Nuryani W, Silvia E, Djatnika I, \& Marwoto B. 2010. Formulasi biopestisida berbahan aktif Bacillus subtilis, Pseudomonas fluorescens, dan Corynebacterium sp. nonpatogenik untuk mengendalikan penyakit karat pada krisan. J. Hort. 20(3): 247-261.

Herlinda S. 2010. Spore density and viability of entomopathogenic fungal isolates from Indonesia, and their virulence against Aphis gossypii Glover (Homoptera: Aphididae). Trop. Life Sci. Res. 21(1): 11-19.

Herlinda S, Darmawan KA, Firmansyah, Adam T, Irsan C, \& Thalib R. 2012. Bioesai bioinsektisida Beauveria bassiana dari Sumatera Selatan terhadap kutu putih pepaya, Paracoccus marginatus Williams \& Granara De Willink (Hemiptera: Pseudococcidae). J. Entomol. Indones. 9(2): 81-87.
Herlinda S, Mulyati SI, \& Suwandi. 2008a. Jamur entomopatogen berformulasi cair sebagai bioinsektisida untuk pengendali wereng coklat. Agritrop 27(3): 119-126.

Herlinda S, SI Mulyati, \& Suwandi. 2008b. Selection of isolates of entomopathogenic fungi and the bioefficacy of their liquid production against Leptocorisa oratorius nymphs. Microbiol. Indones. 2(3): 141-146.

Herlinda S, Irsan C, Mayasari R, \& Septariani S. 2010. Identification and selection of entomopathogenic fungi as biocontrol agents for Aphis gossypii from South Sumatra. Microbiol. Indones. 4(3): 137142.

Herlinda S, Dewi R, Adam T, Suwandi, \& Wijaya A. 2015a. Struktur komunitas laba-laba di ekosistem padi ratun: pengaruh aplikasi Beauveria bassiana (Balsamo). J. Entomol. Indones. 12(2): 91-99.

Herlinda S, Kusuma A, Suwandi, \& Wijaya A. 2015b. Perbandingan efek pemberian bioinsektisida dan ekstrak kompos terhadap produksi padi ratun dan populasi serangga hama. J. Agron. Indones. 43(1): 23-29.

Indarmawan T, Mustopa AZ, Budiarto BR, \& Tarman K. 2016. Antibacterial activity of extracellular protease isolated from an algicolous fungus Xylaria psidii KT30 against gram-positive bacteria. HAYATI Journal of Biosciences 23: 7378.

Karthikeyan A, Shanthi V, \& Nagasathya A. 2008. Effect of different media and $\mathrm{pH}$ on the growth of Beauveria bassiana and its parasitism on leaf eating caterpillars. Res. J. Agric. Biol. Sci. 4(2):117-119.

Nunilahwati H, Herlinda S, Irsan C, Pujiastuti Y, Khodijah, \& Meidelima D. 2013. Uji efikasi bioinsektisida jamur entomopatogen berformulasi cair terhadap Plutella xylostella (L.) di laboratorium. J. HPT Tropika 13(1): 52-60.

Pham TA, Kim JJ, Kim SG, \& Kim K. 2009. Production of blastospore of entomopathogenic Beauveria bassiana in a submerged batch culture. Mycobiology 37(3): 218-224.

Prayogo Y. 2006. Upaya mempertahankan keefektifan cendawan entomopatogen untuk mengendalikan hama tanaman pangan. J. Litbang Pertanian 25(2): 47-54. 
Prayogo Y. 2014. Efikasi cendawan entomopatogen Lecanicillium lecanii terhadap Bemisia tabaci (Hemiptera: Aleyrodidae) pada kedelai. J. HPT Tropika 14(2): 187-200.

Prayogo Y \& Santoso T. 2013. Viabilitas dan infektivitas formulasi cendawan entomopatogen Lecanicillium lecanii sebagai biopestisida pengendalian telur kepik coklat Riptortus linearis. Penelitian Pertanian Tanaman Pangan 32(1): 57 66.

Rachmawaty. 2009. Komparasi enzim kitinase dari Beauveria bassiana galur lokal Sulawesi Selatan terhadap mortalitas ulat grayak (Spodoptera litura). Bionature 10(2): 60-64.

Riyanto, Herlinda S, Irsan C, \& Umayah A. 2013. Spesies-spesies jamur entomopatogen yang menginfeksi Aphis gossypii (Glover) Hemoptera: Aphididae) di agroekosistem sayur dataran rendah dan dataran tinggi Sumatera Selatan. Jurnal Sainmatika 10(2): 1-9.

Soundarapandian P \& Chandra R. 2007. Mass production of endomopathogenic fungus Metarhizium anisopliae (Deuteromycota: Hyphomycetes) in the laboratory. Res. J. Microbiol. 2(9): 690-705.

Srikandace Y, Hapsari Y, \& Simanjuntak P. 2007. Selection of endophytic microbes of Curcuma zedoaria in producing antimicrobial compounds. J. Ilmu Kefarmasian Indonesia. 5: 77-84.
Suprayogi, Marheni, \& Oemry S. 2015. Uji efektifitas jamur entomopatogen Beauveria bassiana dan Metarhizium anisopliae terhadap kepik hijau (Nezara viridula L.) (Hemiptera: Pentatomidae) pada tanaman kedelai (Glycine max L.) di rumah kasa. J. Online Agroekoteknologi 3(1): 320327.

Suryadi Y, Priyatno TP, Samudra IM, Susilowati DN, Lawati N, \& Kustaman E. 2013. Pemurnian parsial dan karakterisasi kitinase asal jamur entomopatogen Beauveria bassiana isolat BB200109. Jurnal AgroBiogen 9(2): 77-84.

Tanada Y \& Kaya HK. 1993. Insect Pathology. Academic Press, Inc., San Diego.

Thalib R, Fernando R, Khodijah, Meidalima D, \& Herlinda S. 2013. Patogenisitas isolat Beauveria bassiana dan Metarhizium anisopliae asal tanah lebak dan pasang surut Sumatera Selatan untuk agens hayati Scirpophaga incertulas. J. HPT Tropika 13(1): 10-18.

Trizelia, Syahrawati MY, \& Mardiah A. 2011. Patogenisitas beberapa isolat cendawan entomopatogen Metarhizium spp. terhadap telur Spodoptera litura Fabricius (Lepidoptera: Noctuidae). J. Entomol. Indones. 8(1): 45-54. 